\title{
Special issue on therapeutic antibodies and biopharmaceuticals
}

Experimental \& Molecular Medicine (2017) 49, e304; doi:10.1038/emm.2017.46; published online 24 March 2017

$\mathrm{C}$ urrently, there are more than 58 antibodies clinically available for the treatment of various diseases, including cancer, chronic inflammation and infection. In 2016, eight antibodies were newly approved, and the annual number of approved antibodies has increased over the past decade. The global biopharmaceutical market has rapidly increased and is expected to reach $25 \%$ of the total global pharmaceutical market this year. Monoclonal antibodies play a critical role in the rapid growth of biopharmaceuticals and currently claim over $25 \%$ of the biopharmaceutical market. Among the 20 drugs with the highest sales in 2014, there were 11 biopharmaceuticals, including six antibodies.

The higher price of biopharmaceuticals compared to smallmolecule drugs has resulted in a significant burden for patients, health insurers and public entities supporting medical costs. In an effort to reduce this financial burden, researchers have actively pursued the introduction of biosimilar antibodies. However, the heterogeneity in the glycosylation of immunoglobulin G(IgG) molecules has been a hurdle. In 2013, the first biosimilar IgG antibody (Infliximab, Celltrion) was approved in Europe. In 2016, two biosimilar antibodies (infliximab-dyyb, Celltrion and adalimumab-atto, Amgen) were approved through the US FDA, and a biosimilar version of trastuzumab (Celltrion) was approved through the MFDS of South Korea.

This rapid growth in the therapeutic monoclonal and biosimilar antibody market prompted the dramatic expansion of eukaryotic cell culture and processing facilities, both within traditional biopharmaceutical companies and in the form of newly recruited entities, such as Celltrion and Samsung Biologics. The classical concept of 'magic bullets,' emphasizing the specific targeting capability of antibodies, was revisited after the success of antibody drug conjugates and chimeric antigen receptor T-cell therapies.

In this special issue, we invited three reviews and two original articles. The Scripps Research Institute (TSRI) has invented or advanced many key concepts in the development of therapeutic antibodies, including phage display, which played a critical role in the invention of many therapeutic antibodies, such as adalimumab. In 2009, TSRI established a new campus in Florida and an institute in Chuncheon, South Korea (Scripps Korea Antibody Institute). One of the major research areas in both institutes is the development of new therapeutic antibodies. I worked with Dr Christoph Rader in the laboratory of the late Dr Carlos F Barbas III of TSRI, who was one of the pioneers in phage display technology and recombinant antibody engineering. Dr Rader has long been a part of the TSRI La Jolla campus and has recently joined the TSRI Florida campus. He played a key role in utilizing rabbits for the generation of recombinant antibodies. Throughout his career, Dr Rader has identified the critical differences between the rabbit B-cell repertoire and those of other animals frequently used for antibody generation, such as mice. Dr Rader has also paved the way for the generation of rabbit monoclonal antibodies using phage display and the humanization of these antibodies for therapeutic purposes. Many humanized rabbit antibodies are now in clinical trial.

As the success of therapeutic antibody technology as a platform in drug development grew, the weaknesses of therapeutic antibodies were slowly revealed. Although the large molecular weight of an antibody guarantees a long half-life inside the human body, this feature also limits its deeper penetration into tissues. In addition, the long half-life occasionally augments toxicity or blurs radioimmuno-scintigraphy images when antibodies are used as imaging agents. Alternative protein scaffolds with adequate molecular weights have the potential to fill the gap between small chemical drugs and antibodies. More than 15 protein scaffolds have been developed, including the affibody, and many of these scaffolds are now being tested in clinical trials. Dr Fredrik Y Frejd is currently the chief scientific officer of Affibody, which has close, well-established relationships with hospitals and other companies in Seoul, including Abclon. Abclon is currently developing affimab, a fusion protein of antibody and affibody. Dr Frejd's review discusses the affibody concept and its applications in imaging and therapy.

Recently, there has been marked investment in the biopharmaceutical industry of South Korea, resulting in the creation of companies such as Celltrion, Samsung Biologics, Samsung 
Bioepis and IsuAbxis. All of these companies have currently exercised their possession of large protein drug production facilities in the development of biosimilar drugs, and these facilities can quickly be switched to the production of new biopharmaceuticals. The South Korean government established not only infrastructures such as the Osong Medical Innovation Foundation, but also two funding agencies, the Korea Drug Development Fund and the National OncoVenture Fund, to support the development of new drugs. Biopharmaceuticals comprise a large portion of the drug candidates supported by these agencies. Such support has enabled South Korean companies to grow in the area of biopharmaceutical development. Among 14 biopharmaceuticals targeting hepatocyte growth factor and the cMet signaling pathway, South Korean companies have developed one cMet-targeting antibody and one hepatocyte growth factor (HGF)-targeting antibody, which have reached the clinical trial phase. Dr Hyori Kim at Asan Hospital reviewed biopharmaceutical drug candidates targeting HGF/cMet.

The National Cancer Center (NCC) in Korea was established in 2000, providing both intramural research programs and extramural research grants. One major goal of the NCC is the discovery of new therapeutic agents for cancer. Over the past 16 years, three therapeutic agents were successfully enrolled in clinical trials supported by the NCC: a gene therapy agent, a T-cell therapy and an HGF-targeting antibody. Dr In-Hoo Kim was previously the director of the NCC Research Institute and successfully launched a program dedicated to bridging basic and clinical research. This program has now become the National OncoVenture Fund. The preclinical development of the HGF-targeting antibody, YYB-101, was supported by the NCC and the National OncoVenture Fund. Dr Kim and
I contributed an article describing the preclinical development of YYB-101 to this special issue.

Recently, next-generation sequencing (NGS) technology has facilitated a massive increase in the capacity to sequence genomes at a relatively low cost and in a short time frame. NGS has revolutionized many aspects of biological research and is being actively adopted for antibody development. An analysis of the entire B-cell repertoire inside a living organism would provide valuable information regarding where immune responses are directed as the organism faces the challenges of infectious agents and cancers. NGS is also becoming a method for screening antibody clones reactive to specific immunogens in a high-throughput manner, which could dramatically change the future of antibody development. One article in this special issue describes the application of NGS to the high-throughput discovery of antibody clones.

Junho Chung

Department of Biochemistry and Molecular Biology, Seoul National University College of Medicine, Seoul, Republic of Korea E-mail: jjhchung@snu.ac.kr

This work is licensed under a Creative Commons Attribution-NonCommercial-ShareAlike 4.0 International License. The images or other third party material in this article are included in the article's Creative Commons license, unless indicated otherwise in the credit line; if the material is not included under the Creative Commons license, users will need to obtain permission from the license holder to reproduce the material. To view a copy of this license, visit http://creativecommons.org/licenses/by-nc-sa/4.0/ 